\title{
Trends in bacteriological profile of neonatal sepsis in Neonatal Intensive Care Unit of a referral center of western Nepal
}

\author{
Bhandari B' ID $ه$, Panthee $\mathrm{K}^{2}, \mathrm{KC} \mathrm{P}^{3}$, Siddique $\mathrm{N}^{4}$
}

'Bikash Bhandari, Lecturer; ${ }^{2}$ Kiran Panthee, Assistant Professor; ${ }^{3}$ Prabal KC, Medical Officer; Rasuwa District Hospital, Rasuwa, Nepal; ${ }^{4}$ Neha Siddique, Intern: Department of Pediatrics, Devdaha Medical College, Rupandehi, Nepal.

\begin{abstract}
Background: Neonatal sepsis is one of the major causes of neonatal morbidity and mortality in developing countries like Nepal. In order to lower the morbidity and mortality of newborns in Neonatal Intensive Care Unit (NICU), it is essential to study the bacteriological profile and antibiotic sensitivity.

Objective: This study aimed to identify the common bacteriological profile and their antibiotics susceptibility pattern in the NICU of medical college of western Nepal.

Methodology: A descriptive cross-sectional study was conducted in NICU of Devdaha Medical College and Research Institute, Nepal among all blood culture positive neonates admitted between April 2020 to September 2020. Convenient sampling was done. All clinically suspected neonates were identified and laboratory data including bacteriological profile and antibiotic sensitivity were recorded and analyzed using Statistical Package for the Social Sciences (SPSS) version 20. Results: Among 215 neonates admitted in the NICU, 45 (20.9\%) had culture positive sepsis. Most isolates were early onset sepsis (62.22\%) and low birth weight (57.78\%). The majority of isolates were Gram positive, predominantly Staphylococcus aureus (37.78\%). Staphylococcus aureus showed higher resistance to Cloxacillin $(57.1 \%)$ and had higher sensitivity to Vancomycin and Linezolid (100\%). Similarly, Gram negative isolates, Escherichia coli and Klebsiella sps, showed higher resistance to Ceftriaxone (100\%) and Cefoperazone, and were highly sensitive to Imipenem (100\%) and Colistin (100\%). Conclusion: Staphylococcus aureus was the most common organism causing neonatal sepsis in current study with increasing resistance to commonly used Cloxacillin and Ampicillin and highly sensitive to Vancomycin and Linezolid. There is higher risk of emergence of antibiotic resistance. Thus, rational use of empirical antibiotics is necessary to prevent drug resistant sepsis.
\end{abstract}

Key words: Antibiotics; Neonatal sepsis; Staphylococcus aureus

Access this article online
Website: www.jkmc.com.np
DOI: https://doi.org/10.3126/jkmc.v9i4.35534
HOW TO CITE
Bhandari B, Panthee K, KC P, Siddique N. Trends in bacteriological
profile of neonatal sepsis in Neonatal Intensive Care Unit of a
referral center of western Nepal. J Kathmandu Med Coll. 2020;9(4):
182-7.

Address for correspondence

Dr. Bikash Bhandari

Lecturer, Department of Pediatrics

Devdaha Medical College, Bhaluhi, Devdaha-9, Rupandehi, Nepal. Email: babu_bhandari@hotmail.com

Copyright $\odot 2020$ Journal of Kathmandu Medical College (JKMC) ISSN: 2019-1785 (Print), 2091-1793 (Online) Attribution-Non Commercial 4.0 International License.

\section{INTRODUCTION}

Teonatal sepsis is the infection of the bloodstream of the newborn less than 28 days of life ${ }^{1}$. It is one of the major causes of mortality and morbidity among neonates in Africa and South Asia. Among these, very low birth weight neonates are at higher risk ${ }^{2,3}$. The World Health Organization (WHO) estimates as per 2017 the global neonatal mortality rate (NMR) is 18 per 1000 live births among these neonatal sepsis accounts $14 \%$ of the deaths $s^{4,5}$. According to Nepal Demographic and Health Survey (NDHS) 2016, NMR in Nepal is 21 per 1000 live births and $16 \%$ of the deaths are due to neonatal sepsis ${ }^{6}$. According to studies done in NICU of different hospitals in Kathmandu Valley, the prevalence of neonatal sepsis ranges from $14 \%$ to $20.5 \%$ and Staphylococcus aureus being the most common causative organism ${ }^{7-9}$.

The risk factor for neonatal sepsis includes premature rupture of membrane, prolonged rupture of membrane, 
low birth weight, prematurity, poor maternal nutrition, birth asphyxia and congenital anomalies ${ }^{10}$. The emergence of antibiotic resistance and a fewer reserve of antibiotics has been a greater challenge in managing neonatal sepsis. There are a limited number of similar researches in Nepal ${ }^{11,12}$.

Thus, the aim of this study is to identify the prevalence, bacteriological profile and antibiotic susceptibility of culture positive neonatal sepsis in the Neonatal Intensive Care Unit (NICU) of Devdaha Medical College and Research Institute.

\section{METHODOLOGY}

This was a descriptive cross-sectional study conducted in the NICU of Devdaha Medical College and Research Institute (DMCRI). The study period was from April, 2020 to September, 2020. Neonates admitted in NICU with clinical features and risk factors suggestive of neonatal sepsis were included in the study with Convenient sampling technique. During the study period, 1729 deliveries were conducted out of which 284 neonates were admitted in NICU. The sample size was 215 neonates who met the inclusion criteria. Sepsis was suspected due to the presence of one or more of the following clinical features like temperature instability, poor feeding, lethargy, respiratory distress (chest retractions, grunting, tachypnea), poor cry, cyanosis, neonatal jaundice, other risk factors like prolonged rupture of membrane and prematurity. The neonates excluded from the study were outborn neonates, very low birth weight and extremely low birth weight neonates and those discharged against medical advice.

Blood was collected using the strict aseptic technique and septic screening was sent as per the NICU protocol of DMCRI. The screening test included complete blood count, blood grouping and Rh-typing, C-reactive protein, blood culture and sensitivity, peripheral smear and chest $x$-ray. Samples for blood culture were collected in Brain Heart Infusion (BHI) medium and overnight incubation at $37^{\circ} \mathrm{C}$ was done. On the second day $1^{\text {st }}$ subculture in blood agar and Mac Conkey agar was done. Antibiotic sensitivity was tested in Mueller Hinton agar for positive growth. Further subcultures were done until the 5th day to give the final report. The culture positive cases and their antibiotic susceptibility pattern were identified and analyzed using SPSS version 20 with frequency table. Chi-square test and Z- test for proportions were used for inferential statistics.

\section{RESULTS}

Among 215 neonates included in this study, 45 (20.9\%) isolates were found to be blood culture positive neonatal sepsis and rest 170 (79.1\%) were culture negative clinically suspected neonatal sepsis.

Among the 215 admitted neonates, 107 (49.77\%) were male and 108 (50.23\%) were female. Twenty two preterm and twenty three term neonates were culture positive ( $p$ value $<0.001$ ). Twenty-six neonates with birth weight $<2500$ grams turned out to be culture positive while 19 neonates with birth weight $\geq 2500$ grams were culture positive ( $p$ value $<0.001$ ). Twenty eight neonates among EOS (Early onset sepsis) and 17 among LOS (Late onset sepsis) were culture positive (Table 1 ).

Respiratory distress including retraction, grunting and tachypnea collectively was the major presenting symptom (32.09\%) for admission of the suspected neonatal sepsis followed by fever (17.67\%), asphyxia (11.16\%), lethargy (10.23\%) and poor feeding (8.84\%). Maternal premature rupture of membranes (PROM) $(7.91 \%)$ also was one of the criteria for suspicion of neonatal sepsis and admission in NICU (Figure 1).

The majority of bacterial isolates were Gram positive (68.89\%) with majority being Staphylococcus aureus (37.78\%) and among Gram negative isolates (31.11\%) majority was Escherichia coli (22.22\%) (Table 2).

Staphylococcus aureus, coagulase negative staphylococcus (CONS) and Escherichia coli were the major organisms responsible for both EOS and LOS. However, Klebsiella sps was found responsible exclusively for LOS ( $p$ value 0.005). CONS and Escherichia coli were major isolates in preterm neonates. Escherichia coli was also significantly responsible for sepsis in low birth weight (LBW) infants ( $p$ value 0.017 ) (Table 3 ).

Linezolid and Vancomycin were found to be the most sensitive among Gram positive organisms. Doxycycline and Gentamicin were found to be sensitive in both Gram positive and Gram-negative organisms. Cefoperazone was found sensitive for Gram positive organisms, however, Escherichia coli and Klebsiella sps were found to be resistant. On further subculture, second line drugs Imipenem and Colistin were found to be highly sensitive against Escherichia coli and Klebsiella sps resistant to Cefoperazone. Ampicillin and Norfloxacin were found to be resistant among the majority of tests (Table 4). 


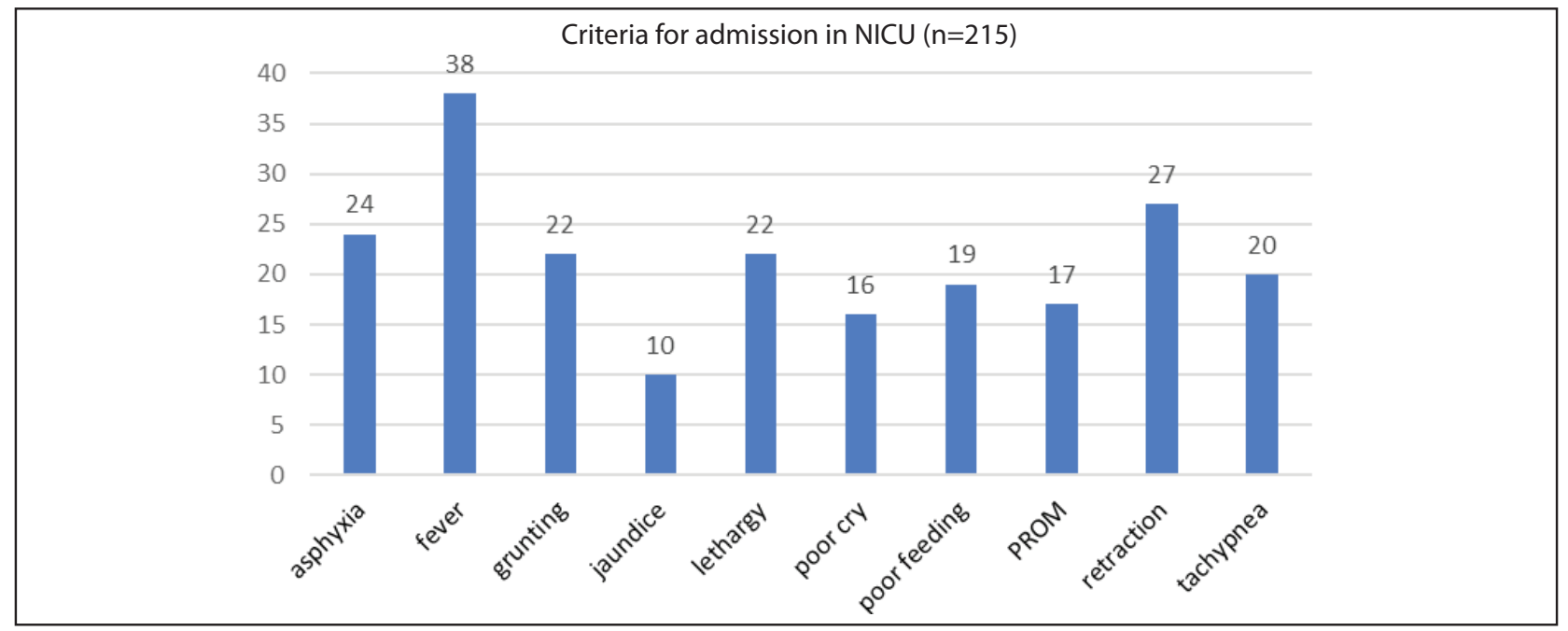

Figure 1: Criteria for admission in NICU for suspected sepsis

\section{Table 1: General characteristics of neonates}

\begin{tabular}{|c|c|c|c|c|}
\hline Variables & Culture negative & Culture positive & Total & p-value \\
\hline \multicolumn{5}{|l|}{ Gender } \\
\hline Male & 86 & 21 & 107 & \multirow{2}{*}{0.640} \\
\hline Female & 84 & 24 & 108 & \\
\hline \multicolumn{5}{|c|}{ Gestational age at birth } \\
\hline Preterm (<37wks) & 28 & 22 & 50 & \multirow{2}{*}{$<0.001^{*}$} \\
\hline Term ( $\geq 37 w k s)$ & 142 & 23 & 165 & \\
\hline \multicolumn{5}{|l|}{ Birth-weight } \\
\hline$<2500 \mathrm{gm}$ & 49 & 26 & 75 & \multirow{2}{*}{$<0.001^{*}$} \\
\hline$\geq 2500 \mathrm{gm}$ & 121 & 19 & 140 & \\
\hline \multicolumn{5}{|l|}{ Onset of symptom } \\
\hline$<72 \mathrm{hrs}$ & 113 & 28 & 141 & \multirow{2}{*}{0.594} \\
\hline$>72 \mathrm{hrs}$ & 57 & 17 & 74 & \\
\hline
\end{tabular}

* Chi-square test significant at $p=<0.05$

Table 2: Distribution of common bacterial isolates $(n=45)$

\begin{tabular}{lcc}
\hline Bacterial isolates & Frequency & Percentage \\
Gram-positive & & 37.78 \\
Staphylococcus aureus & 17 & 22.22 \\
Coagulase-negative staphylococci & 10 & 8.89 \\
Streptococcus pyogenes & 4 & 22.22 \\
Gram-negative & & 8.89 \\
Escherichia coli & 10 & 4 \\
Klebsiella sps & 4 &
\end{tabular}

Table 3: Culture positive isolates based on age at admission, gestational age at birth and birth weight ( $\mathrm{n=45)}$

\begin{tabular}{|c|c|c|c|c|c|c|c|c|c|}
\hline \multirow{2}{*}{ Bacterial isolate } & \multicolumn{3}{|c|}{ Age at admission } & \multicolumn{3}{|c|}{ Gestational age at birth } & \multicolumn{3}{|c|}{ Birth weight } \\
\hline & $<72 \mathrm{hr}$ (EOS) & $>72 \mathrm{hr}$ (LOS) & $\mathbf{p}$ & $<37$ wks & $\geq 37$ wks & $\mathbf{p}$ & $<2500$ gm & $\geq 2500 \mathrm{Gm}$ & $\mathbf{p}$ \\
\hline Staphylococcus aureus & 13 & 4 & 0.327 & 7 & 10 & 0.068 & 9 & 8 & 0.103 \\
\hline CONS & 6 & 4 & 0.704 & 5 & 5 & $0.040^{*}$ & 5 & 5 & 0.303 \\
\hline Escherichia coli & 6 & 4 & 0.704 & 7 & 3 & $<0.001^{*}$ & 7 & 3 & $0.017^{*}$ \\
\hline Streptococcus pyogenes & 3 & 1 & 0.689 & 2 & 2 & 0.201 & 3 & 1 & 0.089 \\
\hline Klebsiella sps & 0 & 4 & $0.005^{*}$ & 1 & 3 & 0.936 & 2 & 2 & 0.522 \\
\hline
\end{tabular}

* Z-test for proportions, significant at $p=<0.05$ 
Table 4: Antibiotic resistance among the common bacterial isolates

\begin{tabular}{|c|c|c|c|c|c|c|c|c|c|c|c|c|c|c|c|c|c|c|c|c|}
\hline \multirow[t]{2}{*}{ Antibiotic } & \multicolumn{4}{|c|}{$\begin{array}{l}\text { Staphylococcus } \\
\text { aureus }(n=17)\end{array}$} & \multicolumn{4}{|c|}{$\begin{array}{l}\text { CONS } \\
(n=10)\end{array}$} & \multicolumn{4}{|c|}{$\begin{array}{l}\text { Escherichia coli } \\
\qquad(n=10)\end{array}$} & \multicolumn{4}{|c|}{$\begin{array}{c}\text { Streptococcus } \\
\text { pyogenes }(n=4)\end{array}$} & \multicolumn{4}{|c|}{$\begin{array}{c}\text { Klebsiella sps } \\
\quad(n=4)\end{array}$} \\
\hline & $\mathbf{S}$ & $\mathbf{R}$ & $\mathbf{U}$ & $\mathbf{R} \%$ & $\mathbf{S}$ & $\mathbf{R}$ & $\mathbf{U}$ & $\mathbf{R} \%$ & $\mathbf{S}$ & $\mathbf{R}$ & $\mathbf{U}$ & $\mathbf{R} \%$ & $\mathbf{S}$ & $\mathbf{R}$ & $\mathbf{U}$ & $\mathbf{R} \%$ & $\mathbf{S}$ & $\mathbf{R}$ & $\mathbf{U}$ & $\mathbf{R} \%$ \\
\hline Linezolid & 15 & 0 & 2 & $0 \%$ & 9 & 0 & 1 & $0 \%$ & 0 & 0 & $10^{*}$ & - & 3 & 0 & 1 & $0 \%$ & 0 & 0 & $4^{*}$ & - \\
\hline Doxycycline & 7 & 0 & 8 & $0 \%$ & 7 & 0 & 3 & $0 \%$ & 10 & 0 & 0 & $0 \%$ & 0 & 0 & $4^{*}$ & - & 4 & 0 & 0 & $0 \%$ \\
\hline Cefotaxime & 11 & 0 & 6 & $0 \%$ & 6 & 0 & 4 & $0 \%$ & 0 & 0 & $10^{*}$ & - & 0 & 0 & $4^{*}$ & - & 0 & 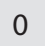 & $4^{*}$ & - \\
\hline Ofloxacin & 9 & 3 & 5 & $25.0 \%$ & 5 & 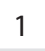 & 4 & $16.7 \%$ & 5 & 0 & 5 & - & 0 & 1 & $3^{*}$ & $100 \%$ & 0 & 0 & $4^{*}$ & - \\
\hline Gentamicin & 11 & 0 & 6 & $0 \%$ & 9 & 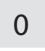 & 1 & $0 \%$ & 10 & 0 & 0 & $0 \%$ & 3 & 1 & 0 & $25 \%$ & 4 & 0 & 0 & $0 \%$ \\
\hline Ceftriaxone & 8 & 3 & 6 & $27.3 \%$ & 4 & 0 & 6 & $0 \%$ & 0 & 10 & 0 & $100 \%$ & 0 & 3 & 1 & $100 \%$ & 0 & 0 & $4^{*}$ & - \\
\hline Vancomycin & 11 & 0 & 6 & $0 \%$ & 9 & 0 & 1 & $0 \%$ & 0 & 0 & $10^{*}$ & - & 3 & 0 & 1 & $0 \%$ & 0 & 0 & $4^{*}$ & - \\
\hline Cefoperazone & 14 & 1 & 2 & $6.67 \%$ & 6 & 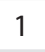 & 3 & $14.3 \%$ & 0 & 5 & 5 & $100 \%$ & 0 & 1 & $3^{*}$ & $100 \%$ & 0 & 4 & 0 & $100 \%$ \\
\hline COT & 2 & 3 & $12^{*}$ & $60.0 \%$ & 2 & 3 & 5 & $60.0 \%$ & 0 & 0 & $10^{*}$ & - & 1 & 2 & 1 & $66.7 \%$ & 0 & 0 & $4^{*}$ & - \\
\hline Cefixime & 11 & 4 & 2 & $26.7 \%$ & 2 & . & 4 & $66.7 \%$ & 4 & 1 & J & $20.0 \%$ & 0 & 0 & $4^{*}$ & - & 0 & 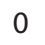 & $4^{*}$ & - \\
\hline Ciprofloxacin & 2 & 0 & $15^{*}$ & $0 \%$ & 2 & 0 & $8^{*}$ & $0 \%$ & 0 & 0 & $10^{*}$ & - & 0 & 1 & $3^{*}$ & $100 \%$ & 4 & 0 & 0 & $0 \%$ \\
\hline Imipenem & 0 & 0 & $17^{*}$ & - & 1 & 1 & $8^{*}$ & $50.0 \%$ & 5 & 0 & 5 & $0 \%$ & 0 & 0 & $4^{*}$ & - & 4 & 0 & 0 & $0 \%$ \\
\hline Tobramycin & 0 & 0 & $17^{*}$ & - & 0 & 0 & $10^{*}$ & - & 5 & 0 & 5 & $0 \%$ & 0 & 0 & $4^{*}$ & - & 0 & 0 & $4^{*}$ & - \\
\hline Trimethoprim & 0 & 0 & $17^{*}$ & - & 0 & 0 & $10^{*}$ & - & 3 & 0 & 7 & $0 \%$ & 0 & 0 & $4^{*}$ & - & 0 & 0 & $4^{*}$ & - \\
\hline Levoflox & 0 & 0 & $17^{*}$ & - & 0 & 0 & $10^{*}$ & - & 5 & 0 & 5 & $0 \%$ & 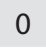 & 0 & $4^{*}$ & - & 0 & 0 & $4^{*}$ & - \\
\hline Colistin & 0 & 0 & $17^{*}$ & - & 0 & 0 & $10^{*}$ & - & 5 & 0 & 5 & $0 \%$ & 0 & 0 & $4^{*}$ & - & (T) & 0 & 0 & $0 \%$ \\
\hline Tetracycline & 2 & 0 & $15^{*}$ & $0 \%$ & 0 & 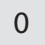 & $10^{*}$ & - & 4 & 1 & 5 & $20.0 \%$ & 0 & 1 & $3^{*}$ & $100 \%$ & 0 & 0 & $4^{*}$ & - \\
\hline Cefipime & 0 & 0 & $17^{*}$ & - & 0 & & $10^{*}$ & 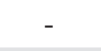 & 0 & 0 & $10^{*}$ & 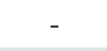 & 1 & 2 & 0 & $75.0 \%$ & 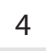 & 0 & . & $0 \%$ \\
\hline $\begin{array}{l}\text { Piperacillin- } \\
\text { Tazo. }\end{array}$ & 4 & 0 & $13^{*}$ & $0 \%$ & 0 & 0 & $10^{*}$ & - & 0 & 0 & $10^{*}$ & - & 1 & 2 & 1 & $66.7 \%$ & 0 & 0 & $4^{*}$ & - \\
\hline Cloxacillin & 3 & 4 & $10^{*}$ & $57.1 \%$ & 0 & 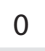 & $10^{*}$ & - & 0 & 0 & 10 & - & . & 0 & $4^{*}$ & - & 0 & 0 & $4^{*}$ & - \\
\hline Ceftazidime & 3 & 1 & $13^{*}$ & $25.0 \%$ & 0 & 0 & $10^{*}$ & 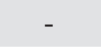 & 0 & 0 & $10^{*}$ & - & 0 & 0 & $4^{*}$ & - & 0 & 4 & 0 & $100 \%$ \\
\hline Carbenicillin & 0 & 0 & $17^{*}$ & - & 0 & 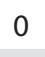 & $10^{*}$ & - & 0 & 0 & $10^{*}$ & - & 2 & 0 & 2 & $0 \%$ & 0 & 0 & $4^{*}$ & - \\
\hline Ampicillin & 0 & 2 & $15^{*}$ & $100 \%$ & 0 & 3 & 7 & $100 \%$ & 0 & 10 & 0 & $100 \%$ & 0 & 1 & $3^{*}$ & $100 \%$ & 0 & 0 & $4^{*}$ & - \\
\hline Norfloxacin & 0 & 4 & $13^{*}$ & $100 \%$ & 0 & r & $9^{*}$ & $100 \%$ & 0 & 0 & $10^{*}$ & - & 0 & 0 & $4^{*}$ & - & 0 & 0 & $4^{*}$ & - \\
\hline
\end{tabular}

$\mathrm{S}=$ Sensitive, $\mathrm{R}=$ Resistant, $\mathrm{U}=$ Untested, $\mathrm{R} \%=\mathrm{R} /(\mathrm{R}+\mathrm{S}) \times 100 \%$

* Antibiotic sensitivity tested in less than $30 \%$ of isolates of given organism

\section{DISCUSSION}

In our study, culture positivity was $20.9 \%$. Similar culture positivity results were noted in different studies done in Patan Hospital during the period of 2006-2007 and 20142017 which showed the culture positivity of $19.56 \%$ and $20.7 \%$ respectively ${ }^{9,13}$. However, similar studies done in Andra Pradesh, India and KIST Medical College, Nepal showed the culture positivity to be $35.2 \%$ and $48 \%$ respectively ${ }^{14,15}$. This variation in studies is most probably due to differences in study design and culture techniques.

Low birth weight and prematurity were found to be the risk factors of culture positive sepsis in this study. This was consistent with the study findings in Dhulikhel Hospital, Nepal ${ }^{16}$. The study done at Chitwan Medical
College Teaching Hospital in Nepal also showed EOS more often than $\operatorname{LOS}^{17}$.

In this study the most common clinical manifestation of neonatal sepsis was respiratory distress (32.09\%). Similar to our study, respiratory distress being the commonest manifestation of neonatal sepsis was seen in the studies done in KIST Medical College, Nepal (54\%), Beni Suef University Hospital, Egypt (26.1\%) and the study done in Andra Pradesh, India ${ }^{14,15,18}$.

The majority of isolates were Gram positive in this study and among them Staphylococcus aureus being the most prevalent (37.78\%). This was similar to the studies done in Nigeria and India, both of which showed Staphylococcus aureus, the most common bacteria associated with 
neonatal sepsis ${ }^{19,20}$. In contrast, studies done in Patan Hospital and Dhulikhel Hospital, Nepal showed the preponderance of Gram negative organisms of which Klebsiella sps was the most common isolate ${ }^{9,16}$. The reason for variation in this sort of bacterial sepsis could be due to difference in study population, hand hygiene, adherence to infection prevention and its control measures.

In this study the majority of organisms had developed resistance to the commonly used antibiotics like Ampicillin, Cloxacillin, Norfloxacin and some extent to Ceftriaxone. However, Cefotaxime had relatively better coverage to all the organisms. Gentamicin and Doxycycline had standard antibiotic coverage among all the isolates with relatively higher susceptibility to Gram negatives, Escherichia coli and Klebsiella sps. This helped us to change the first line drug to Cefotaxime and Amikacin. This result is consistent with various studies done in Nepal and Pakistan ${ }^{9,13,16,21 .}$

In this study, Gram positive isolates were found to be highly susceptible (100\%) to Vancomycin and Linezolid similar to the study done by Shah AJ et al., Muley VA et al. and Thapa $S$ et al. ${ }^{17,22,23}$. Similarly, among Gram negative isolates, they were found to be resistant to Cefoperazone and on further subculture, those were found to be highly sensitive to Imipenem and Colistin. This was consistent with the study done by Pokhrel B et al. and Yusuf D et al. in Jordan ${ }^{9,24}$.

Escherichia coli being the second most common and the commonest Gram-negative isolates was found to be highly sensitive to Doxycycline and Gentamicin along with Imipenem and Colistin for second line regimen. However, in our study Escherichia coli was resistant to Ampicillin and Ceftriaxone. This indicates the emergence of resistance in the newer strains of Escherichia coli.

The overall mortality among culture positive isolates in our study was $6.67 \%$ and that in the study done by Thapa B et al. and Pokhrel B et al. showed $8.06 \%$ and $15.94 \%$ respectively ${ }^{9,25}$. This variation is most probably due to different geographical location, sample size, and the difference in treatment protocol in the institutes.

\section{RFERENCES}

1. Singh M, Gray CP. Neonatal Sepsis. StatPearls.2020. [PubMed]

2. Seale $A C$, Blencowe $H$, Manu $A A$, Nair $H$, Bahl $R$, Qazi SA, Zaidi AK, Berkley JA, Cousens SN, Lawn JE. Estimates of possible severe bacterial infection in neonates in sub-Saharan Africa, south Asia, and
Since the study is cross sectional and a single center based, limited to small population and sample size, we cannot generalize this result to represent the larger population. All the outborn neonates were excluded in the study due to the limited number of NICU beds and high delivery rate in our institute. This helps us to know the need of larger multicentered prospective studies to validate our result.

\section{CONCLUSION}

According to our study, Gram positive isolates were predominant in all EOS/LOS, preterm/term and LBW/ normal birth weight groups. Both Gram positive and negative isolates showed emerging resistance to the commonly used antibiotics. Based on our study, Cefotaxime and Amikacin can still be used as first line therapy and Meropenem and Vancomycin can be reserved for second line therapy. The use of broadspectrum antibiotics can be devastating if used for a long time and can develop antibiotic resistance. As already in our study, Staphylococcus aureus has developed resistance to Cloxacillin and Escherichia coli has developed resistance to Ceftriaxone and Cefoperazone, this can on long run be responsible for mortality and morbidity in neonates. Thus, to prevent the emergence of drug resistance and neonatal morbidity and mortality, inadvertent use of antibiotics should be avoided, sample collection and laboratory analysis techniques should be improved, rational use of antibiotics and standard neonatal treatment protocol should be implemented in every NICU.

\section{ACIKNOWLEDGEMENTS}

Our sincere thanks and acknowledgment to all the faculties and nursing staff of the Department of Pediatrics and to the faculties and staff of the Department of Microbiology to make this study successful. At last but not the least, our sincere gratitude and thanks to all the neonates and their parents, without them this research would not have been possible.

\section{Conflict of interest: None Source of funding: None}

Latin America for 2012: a systematic review and meta-analysis. The Lancet infectious diseases. 2014 Aug 1;14(8):731-41. [PubMed | Full Text | DOI]

3. Mukhopadhyay S, Puopolo KM. Neonatal earlyonset sepsis: epidemiology and risk assessment. NeoReviews. 2015 Apr 1;16(4):e221-30. [ Full Text | DOI ] 
4. Hug L, Alexander M, You D, Alkema L, for Child UI. National, regional, and global levels and trends in neonatal mortality between 1990 and 2017, with scenario-based projections to 2030: a systematic analysis. The Lancet Global Health. 2019 Jun 1;7(6):e710-20. [ PubMed | Full Text | DOI ]

5. World Health Organization. World health statistics 2019: monitoring health for the SDGs, sustainable development goals. [ Full Text ]

6. Ministry of Health, Nepal; New ERA; and ICF.2017. Nepal Demographic and Health Survey 2016. Kathmandu, Nepal: Ministry of Health, Nepal. [ Full Text ]

7. Yadav NS, Sharma S, Chaudhary DK, Panthi P, Pokhrel P, Shrestha A, Mandal PK. Bacteriological profile of neonatal sepsis and antibiotic susceptibility pattern of isolates admitted at Kanti Children's Hospital, Kathmandu, Nepal. BMC research notes. 2018 Dec 1;11(1):301. [PubMed | Full Text | DOI ]

8. Chapagain RH, Acharya R, Shrestha N, Giri BR, Bagale BB, Kayastha M. Bacteriological Profile of Neonatal Sepsis in Neonatal Intermediate Care Unit of Central Paediatric Referral Hospital in Nepal. Journal of Nepal Health Research Council. 2015;13(31):205. [PubMed | Full Text ]

9. Pokhrel B, Koirala T, Shah G, Joshi S, Baral P. Bacteriological profile and antibiotic susceptibility of neonatal sepsis in neonatal intensive care unit of a tertiary hospital in Nepal. BMC pediatrics. 2018 Dec 1;18(1):208. [ PubMed | Full Text | DOI ]

10. Prabhu K, Bhat S, Rao S. Bacteriologic profile and antibiogram of blood culture isolates in a pediatric care unit. Journal of laboratory physicians. 2010 Jul;2(2):85.[ PubMed | Full Text | DOI ]

11. Aslam B, Wang W, Arshad MI, Khurshid M, Muzammil S, Rasool MH, Nisar MA, Alvi RF, Aslam MA, Qamar MU, Salamat MK. Antibiotic resistance: a rundown of a global crisis. Infection and drug resistance. 2018;11:1645. [PubMed | Full Text | DOI ]

12. Acharya KP, Wilson RT. Antimicrobial resistance in Nepal. Frontiers in medicine. 2019 May 24;6:105. [PubMed | Full Text | DOI ]

13. Shrestha S, Adhikari N, Rai BK, Shreepaili A. Antibiotic resistance pattern of bacterial isolates in neonatal care unit. Journal of the Nepal medical Association. 2010 Oct 1;50(180). [ PubMed | Full Text | DOI ]

14. Kurma VR, Raju MS, Manchu T, Manchu K. Neonatal sepsis: Clinical spectrum, bacteriological profile and antibiotic sensitivity patterns in neonatal intensive care unit in a tertiary care Hospital. Int J Contemp Med Res. 2019;6(6):F1-48. [ Full Text | DOI ]
15. Lakhey A, Shakya H. Role of sepsis screening in early diagnosis of neonatal sepsis. Journal of Pathology of Nepal. 2017 Mar 30;7(1):1103-10. [ Full Text | DOI ]

16. Shrestha S, Shrestha NC, Singh SD, Shrestha RP, Kayestha S, Shrestha M, Thakur NK. Bacterial isolates and its antibiotic susceptibility pattern in NICU. Kathmandu university medical journal. 2013;11(1):66-70. [ PubMed | Full Text | DOI ]

17. Thapa S, Sapkota LB. Changing trend of neonatal septicemia and antibiotic susceptibility pattern of isolates in Nepal. International journal of pediatrics. 2019 Feb 6;2019. [ PubMed | Full Text | DOI ]

18. Fahmey SS. Early-onset sepsis in a neonatal intensive care unit in Beni Suef, Egypt: bacterial isolates and antibiotic resistance pattern. Korean journal of pediatrics. 2013 Aug;56(8):332. [ PubMed | Full Text | DOI ]

19. Peterside O, Pondei K, Akinbami FO. Bacteriological profile and antibiotic susceptibility pattern of neonatal sepsis at a teaching hospital in Bayelsa state, Nigeria. Tropical medicine and health. 2015 Sep;43(3):183-90. [ PubMed | Full Text | DOI ]

20. Sharma P, Kaur P, Aggarwal A. Staphylococcus aureus-the predominant pathogen in the neonatal ICU of a tertiary care hospital in Amritsar, India. Journal of clinical and diagnostic research: JCDR. 2013 Jan;7(1):66. [ PubMed | Full Text | DOI ]

21. Mahmood A, Karamat KA, Butt T. Neonatal sepsis: high antibiotic resistance of the bacterial pathogens in a neonatal intensive care unit in Karachi. J Pak Med Assoc. 2002 Aug;52(8):348-50. [ PubMed | Full Text ]

22. Muley VA, Ghadage DP, Bhore AV. Bacteriological profile of neonatal septicemia in a tertiary care hospital from Western India. Journal of Global Infectious Diseases. 2015 Apr;7(2):75. [ PubMed | Full Text | DOI ]

23. Shah AJ, Mulla SA, Revdiwala SB. Neonatal sepsis: high antibiotic resistance of the bacterial pathogens in a neonatal intensive care unit of a tertiary care hospital. Journal of clinical neonatology. 2012 Apr;1(2):72. [ PubMed | Full Text | DOI ]

24. Yusef D, Shalakhti T, Awad S, Algharaibeh HA, Khasawneh W. Clinical characteristics and epidemiology of sepsis in the neonatal intensive care unit in the era of multi-drug resistant organisms: a retrospective review. Pediatrics \& Neonatology. 2018 Feb 1;59(1):35-41. [ Full Text | DOI ]

25. Thapa B, Thapa A, Aryal DR, Thapa K, Pun A, Khanal $S$, Mahat K. Neonatal sepsis as a major cause of morbidity in a tertiary center in Kathmandu. Journal of Nepal Medical Association. 2013;52(192). [ PubMed | Full Text | DOI ] 